\title{
Irish Travellers and forensic mental
}

\section{health}

Sally Linehan, Dearbhla Duffy, Helen O'Neill, Conor O'Neill, Harry G Kennedy

Ir J Psych Med 2002; 19(3): 76-79

\section{Abstract}

Objectives: To determine whether Irish Travellers are over-represented amongst transfers from prison to psychiatric hospital. If so, to determine whether this represents an excess over the proportion of Irish Travellers committed to prison.

Method: Irish Travellers admitted to the National Forensic Psychiatry service were identified from a case register over three years 1997-1999. New prison committals were sampled and interviewed as part of the routine committal screening to identify ethnicity.

Results: Irish Travellers accounted for $3.4 \%$ of forensic psychiatric admissions compared to $0.38 \%$ of the adult population. Travellers transferred from prison to psychiatric hospital had more learning disability and less severe mental illness than other groups, while black and other ethnic minorities had a higher proportion of severe mental illness. Travellers accounted for $6 \%(95 \% \mathrm{Cl} 3-11)$ of 154 male committals and $4 \%(95 \% \mathrm{Cl} 2-12)$ of 70 female committals. The estimated annualised prison committal rate was $2.8 \%(95 \% \mathrm{Cl} 2.4-3.3)$ of all adult male Travellers in Ireland and $1 \%$ for female Travellers $(95 \% \mathrm{CI}$ 0.8-1.3). Male Travellers had a relative risk of imprisonment compared to the settled community of 17.4 (95\% Cl 2.3-131.4), the relative risk for female Travellers was 12.9 (95\% Cl 1.7-96.7). Imprisoned Travellers had greater rates of drugs and alcohol problems than other prisoners (Relative risk 1.46, 95\% $\mathrm{Cl} 1.11-1.90$ ).

Conclusion: There is gross over-representation of Travellers in forensic psychiatric admissions. This reflects the excess of Travellers amongst prison committals.

Key words: Irish Travellers; Ethnic minorities; Prison; Forensic Psychiatry; Drugs; Alcohol.

Black and minority ethnic groups are commonly over-represented amongst those formally detained under mental health legislation, and this is most pronounced in secure forensic institutions. ${ }^{1,2}$ Research has shown differential representation of ethnic subgroups in the criminal justice process. Black

Sally A Linehan, Research Registrar, Dearbhla M Duffy, Research Registrar, Helen O'Neill, Consultant Forensic Psychiatrist, Conor O'Neill, Senior Registrar, *Harry G Kennedy, Consultant Psychiatrist, Central Mental Hospital, Dundrum, Dublin 14, Ireland.

${ }^{*}$ Correspondence

SUBMITTED: SEPTEMBER 10, 2001. ACCEPTED: MAY 13, 2002. adult males in the UK of African and Caribbean origin were imprisoned at 6.7 times the age-adjusted rate of white males in $1991{ }^{3}$ African American men are estimated to be imprisoned at a rate six times that of white men. ${ }^{4}$

Travellers are a small indigenous ethnic minority, documented as being part of Irish society for centuries. They have a long shared history and value system, which make them a distinct group. They have their own language, customs and traditions. The distinctive Traveller lifestyle and culture based on a nomadic tradition sets Travellers apart from the sedentary population or 'settled people'.

Travellers are widely acknowledged as one of the most marginalised and disadvantaged groups in Irish society. Travellers fare poorly on every indicator used to measure disadvantage: unemployment; poverty; social exclusion; health status; infant mortality; life expectancy; accommodation and living conditions. ${ }^{6,7}$

In Ireland, Travellers are recognised as a distinct group for census purposes and Pavee Point supported the proposal to include an ethnic question for all in the 2002 census. $^{8}$

The processes of stigmatisation and institutional disadvantage are of particular importance in psychiatry. Stigma can arise from and also contribute to mental disorders, leading to disadvantages in housing, employment and direct or indirect criminalisation. ${ }^{9}$ Even those with non-psychiatric disorders such as epilepsy can find themselves over-represented in the criminal justice system if their illness is sufficiently stigmatising. ${ }^{10}$ The opportunity to study processes of criminalisation in a discrete ethnic group who are not distinguished in the usual ways by colour or nationality is therefore instructive.

We hypothesised that if there is an excess of travellers admitted to the Central Mental Hospital, it is a passive reflection of the proportion of travellers committed to the Irish prison system.

\section{Method}

There are about 4,790 Traveller families or an estimated 21,158 Travellers in Ireland based on figures compiled by the Department of Environment and local housing authorities. ${ }^{11,12}$ This is an annual count of Traveller families in:

- Local authority or local authority assisted accommodation

- On the roadside

- Other private accommodation.

This figure is a more accurate estimate of the Traveller population than the 1996 population census figures, because it includes settled Travellers. The 1996 census showed that the Traveller community has a markedly different age and sex structure from that of the population in general. ${ }^{12}$ Within the Traveller population 50\% were aged under 15 
Table 1: Diagnosis and ethnicity for all admissions to the CMH, 1997-1999

\begin{tabular}{|c|c|c|c|c|}
\hline & $\begin{array}{l}\text { White European } \\
\text { No. } \\
\%(95 \% \text { CI })\end{array}$ & $\begin{array}{l}\text { Black \& ethnic minorities } \\
\text { №. } \\
\%(95 \% \text { CI })\end{array}$ & $\begin{array}{l}\text { Travellers } \\
\text { No. } \\
\%(95 \% \text { CI })\end{array}$ & Total \\
\hline $\begin{array}{l}\text { Minor mental illness } \\
\% \text { of total within } \\
\text { ethnicity and } 95 \% \mathrm{CI}\end{array}$ & $\begin{array}{c}92 \\
20.7(17.2 \text { to } 24.7)\end{array}$ & $\begin{array}{c}2 \\
16.7(4.7-44.8)\end{array}$ & $\begin{array}{c}8 \\
28.6(15.3-47.1)\end{array}$ & 102 \\
\hline Severe mental illness & $\begin{array}{c}184 . \\
41.4(37.0-46.1)\end{array}$ & $\begin{array}{c}10 \\
83.3(55.2-95.3)\end{array}$ & $\begin{array}{c}6 \\
21.4(10.2-29.5)\end{array}$ & 200 \\
\hline $\begin{array}{l}\text { Personality disorder or } \\
\text { paraphilia }\end{array}$ & $\begin{array}{c}112 \\
25.2(21.4-39.5)\end{array}$ & $\begin{array}{c}0 \\
0(0-24.3)\end{array}$ & $\begin{array}{c}7 \\
25.0(12.7-43.4)\end{array}$ & 119 \\
\hline Learning disability & $\begin{array}{c}15 \\
3.4(2.1-5.5)\end{array}$ & $\begin{array}{c}0 \\
0(0-24.3)\end{array}$ & $\begin{array}{c}6 \\
21.4(10.2-39.5)\end{array}$ & 21 \\
\hline Substance abuse & $\begin{array}{c}41 \\
9.2(6.9-12.3)\end{array}$ & $\begin{array}{c}0 \\
0(0-24.3)\end{array}$ & $\begin{array}{c}1 \\
3.6(0.6-17.7)\end{array}$ & 42 \\
\hline Total & 444 & 12 & 28 & 484 \\
\hline
\end{tabular}

years, only $1.3 \%$ were over 65 , and $49 \%$ were male. Travellers account for about $0.38 \%$ of the adult population. From these figures we calculate that there are 10,441 Travellers aged 15-65. There were 2,352,781 adults aged 15-65 in the total Irish population at the 1996 census.

A computerised case register of all admissions to the Central Mental Hospital for the three years 1997-1999 was compiled from a written register and cross-checked with ward admission records. During the study period, all transfers from the prisons to mental hospital in the State were to the Central Mental Hospital. There were 476 admissions of 352 individuals during the three-year period. Ethnicity was elicited from records and corroborated by consultation with staff to minimise the risk of under-estimation of Traveller numbers. Patients were classified as white European (to include European Union nationals but excluding Irish Travellers, thereby encompassing those not stigmatised by colour or ethnicity), black and other minority ethnic groups (to coincide with stigmatised groups) and Irish Travellers.

Discharge diagnosis was recorded for each patient according to the ICD-10 multi-axial system based on the multi-disciplinary team assessment and information from independent informants. No formal research instrument was in use.

The study of prison committals was carried out at Cloverhill Prison, the largest remand prison for the country, and the Dochas Centre Mountjoy Prison, the largest women's prison. All new committals were interviewed as part of the routine health screening of all individuals received at the prison, by a nurse and also by a researcher who was a post-membership psychiatrist. Ethnicity was elicited by self-definition. A history of drugs and alcohol problems was elicited by direct questioning for clinical purposes, to elicit those likely to require detoxification. As a check on the reliability of these selfreports, routine urine checks showed that of 86 reporting an opiate problem who had urine checks, 79 (92\%) were positive. Those who did not have urine checks were previously known to the prison staff. Self-report on committal appears
Table 2: Committal screening sample from Clover Hill Prison (males) and the Dochas centre, Mountjoy (females)

$\begin{array}{lccc}\text { Ethnic group } & \begin{array}{c}\text { Males } \\ \text { No } \\ \%(95 \% \text { CI })\end{array} & \begin{array}{c}\text { Females } \\ \text { No } \\ \%(95 \% \text { CI })\end{array} & \begin{array}{c}\text { Total } \\ \text { No } \\ \%(95 \% \text { CI })\end{array} \\ \begin{array}{lccc}\text { White European } \\ \text { excl. Travellers }\end{array} & \begin{array}{c}142 \\ 92 \%(87 \%-96 \%)\end{array} & \begin{array}{c}53 \%(72 \%-90 \%) \\ 89 \%(85 \%-93 \%)\end{array} \\ \begin{array}{l}\text { Black and other } \\ \text { minority ethnic }\end{array} & 2 \%(1 \%-6 \%) & 13 \%(70-23 \%) & 5 \%(3 \%-9 \%) \\ \text { groups } & & & 12 \\ \text { Travellers } & 9 & 3 & 12 \\ & 6 \%(3 \%-11 \%) & 4 \%(2 \%-12 \%) & 5 \%(3 \%-9 \%) \\ \text { Totals } & 154 & 70 & 224\end{array}$

to be reliable for opiates and is likely to be reliable for alcohol and other substances.

There were 352 new committals to Cloverhill prison over the four weeks from October 9-November 5, 2000. New committals to Cloverhill Prison (154 male remands) were screened jointly by a researcher and a nurse employed by the prison service over this period. On 21 sampling days, chosen to be equivalent to three weeks continuous sampling, all new committals were jointly screened. None of those screened were committed twice during the study period. Similarly there were 146 new female committals during the six-week sampling period between October 2 and November 12, 2000. None was committed twice during the study period. On 21 days chosen to be equivalent to three weeks continuous sampling, 70 women were jointly screened.

\section{Results}

\section{Admissions to the Central Mental Hospital}

There were 28 admissions of Travellers, or $4.7 \%$ of the total 476 in the three years 1997-1999. Over the same period, there were 12 admissions (2.5\% of total) of individu- 
Table 3: Annualised committal rate per 100,000 for adults ( $>15$ years)

\begin{tabular}{|c|c|c|c|}
\hline \multirow[t]{2}{*}{$\begin{array}{l}\text { per } 100,000 \text { adults } \\
\text { per annum }\end{array}$} & Male rate & Female rate & $\begin{array}{c}\text { Relative risk } \\
\text { Males v Females }\end{array}$ \\
\hline & $\begin{array}{c}\text { No } \\
(95 \% \text { CI) }\end{array}$ & $\begin{array}{c}\text { No } \\
(95 \% \text { CI) }\end{array}$ & $\begin{array}{c}\text { No } \\
\text { (95\% CI) }\end{array}$ \\
\hline General population & $\begin{array}{c}186 \\
(179-193)\end{array}$ & $\begin{array}{c}83 \\
(78-88)\end{array}$ & $\begin{array}{c}2.22 \\
(0.9-5.4)\end{array}$ \\
\hline Travellers & $\begin{array}{c}2800 \\
(2400-3300)\end{array}$ & $\begin{array}{c}1000 \\
(800-1300)\end{array}$ & $\begin{array}{c}2.9 \\
(0.8-10.6)\end{array}$ \\
\hline $\begin{array}{l}\text { Relative risk travellers } \\
\text { v general population } \\
(95 \% \text { Cl) }\end{array}$ & $\begin{array}{c}17.4 \\
(2.3-131.4)\end{array}$ & $\begin{array}{c}12.9 \\
(1.7-96.7)\end{array}$ & \\
\hline
\end{tabular}

als from black or other minority ethnic groups, including those from European countries outside the European Union. Taking the most conservative estimate by excluding re-admissions, these represent 12 individual Travellers out of 352 individuals admitted or $3.4 \%$ of individuals admitted over the three years 1997-1999 (95\% Cl 2.0-5.9). Similarly, the 12 admissions of black patients represent 10 individuals out of the 352 people admitted $(2.8 \%, 95 \% \mathrm{Cl} 1.6-5.1)$. White Europeans (ie. white Irish and other EU nationals, who would not be expected to incur any stigma due to race or ethnicity), accounted for 330 of the 352 individuals admitted (93.8\%, 95\% Cl 90.7-95.8).

Travellers compared to other admissions to the Central Mental Hospital had less severe mental illness than white Europeans, and more learning disability. Black and other ethnic minorities had a marked excess of severe mental illness when compared with other groups (see Table 1).

When the gravity of the offence for which the patient was imprisoned was compared across ethnic groups, no significant differences emerged.

\section{Prison committals}

Travellers accounted for $6 \%(95 \% \mathrm{Cl} 3-11)$ of male prison committals and $4 \%(95 \% \mathrm{Cl} 2-12)$ of female committals (see Table 2). The annualised committal rate for male Travellers was 2.8\% (95\% Cl 2.4-3.3) of all adult male Travellers in Ireland and $1 \%$ for adult female Travellers $(95 \% \mathrm{Cl} 0.8$ 1.3). Male Travellers had a relative risk of imprisonment compared to the settled community of 17.4 (95\% Cl 2.3-131.4), 12.9 for female Travellers (95\% Cl 1.7-96.7) (see Table 3).

Comparing remanded male Travellers with remanded white Europeans (ie. from within the EU), for self-reported drugs and alcohol problems combined (see Table 4), imprisoned Travellers are significantly more likely to report problems with drugs and alcohol (relative risk 1.46, 95\% Cl 1.11-1.9).

\section{Discussion}

The ethnicity of all new committals to Cloverhill
Prison was elicited by self-definition in this study. The ethnicity of admissions to the Central Mental Hospital was ascertained retrospectively, by review of medical records and staff appraisal. It is possible that the number of Travellers admitted to the Central Mental Hospital was an underestimate of the true rate of admissions. The task force report on the Travelling community recommended that all health data systems should include a question on ethnic group. This would facilitate data collection and proper health planning for all ethnic minorities, including Travellers.

The prison sample was equivalent to three weeks continuous sampling. This represents only a small proportion of committals to Cloverhill Prison annually. A further longitudinal study of committals is warranted to confirm our initial finding of the over-representation of Travellers among committals to remand centres.

Detection of psychiatric illness may have been hampered by the lack of a standardised screening tool for diagnosis of illness. The environment in which screening took place in the prison did not afford privacy and confidentiality to prisoners. This may have resulted in inadequate disclosure of illness to the researchers. We have therefore only reported the discharge diagnosis for those admitted to the Central Mental Hospital.

Our study confirms our original hypotheses that Irish Travellers, as an ethnic group, represent a disproportionate number of those admitted to the Central Mental Hospital and that both male and female Travellers have significantly higher prison committal rates than the general population. This over-representation might be an artefact if the number of Travellers in the adult population is substantially underestimated, but this would require approximately $95 \%$ of Travellers to have been missed in population estimates, and Travellers would have to account for almost $7 \%$ of the adult population. Our findings are similar to studies of ethnic minorities in other jurisdictions and highlight the differential representation of minority ethnic groups in the criminal justice process.

Although Travellers and other ethnic minorities are significantly over-represented in the admissions to the Central Mental Hospital, these hospital admissions are merely following the pattern of over-representation amongst prison committals. The extremely high imprisonment rate for the Traveller community as a whole should be confirmed in a larger study. These rates suggest that a very high proportion of all Travellers will be imprisoned at some time during their life. This 'normalisation' of the experience of imprisonment exposes a high proportion of all Travellers to the adverse health and lifestyle behaviours prevalent in prisons. Prison populations are at great risk of developing opiate and other drug dependence disorders, with associated problems. ${ }^{13}$ In a more gender, elderly age, non-smoking status), consider decreased starting dose. Contra-indications: Known hypersensitivity to any ingredient. Known risk of narrow-
angle glaucoma. Warnings and Special Precautions: angle glaucoma. Warnings and Special Precautions
Clinical monitoring advisable in diabetic patients and tic hypertrophy, or paralytic ileus and related conditions Improvement in clinical condition may take several days lo some weeks. Phenylalanine: Velotabs contain aspatame - a source of phenylalanine. Sodium methyl
parahydroxybenzoate and sodium propyl parahydroxycause urticaria, contact dermatitis and, rarely, imm diate reactions with bronchospasm. Caution in patien with elevated ALT and/or AST, hepatic impairment, limited hepatic functional reserve, and in patients being treated with hepatotoxic drugs. Where hepatitis has
been diagnosed, discontinue zyprexa. Caution in bone marrow depression, and in patients with hypereosinophilic conditions or with myeloproliferative disease Discontinue if signs and symptoms indicative of NMS or unexplained high fever. Caution in patients who have a history of seizures or are subject to factors which may
lower the seizure threshold. If tardive dyskinesia appears, consider dose reduction or discontinuation. Caution when taken with other centrally acting drugs
and alcohol. May antagonise effects of dopamine agoists. Blood pressure should be measured periodicaly in patients over 65 years. As with other antipsychotics, QTc interval, especially in the elderly in patients with congenital long QT syndrome, congestive heart failure heart hypertrophy, hypokalaemia or hypomagnesaemia In clinical trials, olanzapine was not associated with persistent increase in absolute QT intervals,
Interactions: Metabolism may be affected by subInteractions: Metabolism may be affected by sub-
stances that can specifically induce (eg, concomitant smoking or carbamazepine) or inhibit (eg, fluvoxamin the isoenzyme P450-CYP1A2 which metabolises olanoral olanzapine. Olanzapine may antagonise the effects of direct and indirect dopamine agonists. Olanzapin showed no interaction when co-administered with lithi-
um or biperiden. Pregnancy and Lactation: Should be he potential risk to the foetus. Patients should be advised not to breast-feed an infant if they are taking Zyprexa. Driving, etc: May cause somnolence.
Patients should be cautioned about operating hazPatients should be cautioned about operating haz-
ardous machinery, including motor vehicles ing and investigations: Blood and lymphatics. Common
(1-10\%): eosinophilia. Neutropenia was seen in a valproate combination therapy trial in bipolar mania
patients; a potential contributing factor could be high lasma valproate levels. Metabolism and nutrition Very common (>10\%): weight gain. Common (1-10\%) $1.0 \%$ for olanzapine versus $0.9 \%$ for placebo for nonfasting levels $211 \mathrm{mmol} / /)$, elevated triglyceride levels.
Nenvous. Very common ( $>10 \%$ : somnolence, abnormal Nervous. Very common (>10\%): somnolence, abnorma:
gait in Alzheimer's disease patients. Common (1-10\%) gait in Alzheimer's disease patients. Common (1-10\%)
dizziness, akathisia (olanzapine-treated patients had dizziness, akathisia (olanzapine-treated patients had a
lower incidence of parkinsonism, akathisia and dystonia compared with titrated doses of haloperidol. Worsening of Parkinsonian symptomatology and halluParkinson's disease. Cardiac. Uncommon (0.1-1\%) bradycardia, with or without hypotension or syncope Vascular. Common (1-10\%): orthostatic hypotension.
Gastro-intestinal. Common (1-10\%): mild, transient, anticholinergic effects, including constipation and dry mouth. Hepato-biliary. Common (1-10\%): transient
asymptomatic elevations of ALT. AST. Skin and subcuasymptomatic elevations of ALT, AST. Skin and subculaneous tissue. Uncommon (0.1-1\%): photosensitivity
reaction. General. Common (1-10\%): asthenia, oedema. Investigations. Very common (>10\%): elevated tations (eg, gynaecomastia, galactorrhoea, breast enlargement) were rare. Uncommon (0.1-1\%): high creatine phosphokinase. Post-marketing spontaneous
reporting: Blood and lymphatics. Rare (0.01-0.1\%): leureporting: Blood and lymphatics. Rare
copenia. Very rare $(<0.01 \%)$ : thrombocytopenia Immune system disorder. Very rare $(<0.01 \%)$ : allergic eaction. Metabolism and nutritional. Very rare ing diabetes occasionally associated with ketoacidosis or coma, including some fatal cases
Hypertriglyceridaemia. Nervous. Rare (0.01-0.1\%) isk factors. Very rare $(<0.01 \%)$ : cases repores or NMS Siscors. Vtinuation gradual tapering of the dose should be considered. Gastro-intestinal. Very rare $(<0.01 \%)$ : pancreatits. Hepato-biliary. Very rare $(<0.01 \%)$ : hepatitis. Skin and
subcutaneous tissue. Rare $(0.01-0.1 \%)$ : rash. subcutaneous tissue. Rare $(0.01-0.1 \%)$ : rash
Reproductive. Very rare $(<0.01 \%)$ : priapism. For further EU/1/96/022/004 EU/1/96/022/006 EU/1/96/022/1009 UU/1/96/022/010 EU/1/96/022/012 EU/1/99/125/00 EU/1/99/125/003. Date of Prescribing Information is Available From: Eli Lill and Company Limited Dextra Court, Chapel Hill Basingstoke, Hampshire, RG21 5SY Tel: Basingstoke $01256) 315000$ or Eli Lilly and Company (Ireland)
imited, Hyde House, 65 Adelaide Road, Dublin Limited, Hyde House, 65 Adelaide Road, Dublin 2 ,
Republic of Ireland Tel: Dublin 6614377 . "ZYPREXA (olanzapine) and VELOTAB are trademarks of Eli Lily Schizophrenia Research 1999; 36(1-3): 183. website: www.elililly.ie

II

Zyprexa is manufactured in Cork. 


\begin{tabular}{|c|c|c|c|}
\hline & $\begin{array}{l}\text { White EU } \\
\text { nationals }\end{array}$ & Irish Travellers & $\begin{array}{c}\text { Relative Risk } \\
\text { (95\% CI) }\end{array}$ \\
\hline Total No. & 142 & 9 & \\
\hline Alcohol & $34(24 \%)$ & $4(44 \%)$ & $1.80(0.80-4.00)$ \\
\hline Opiates & $53(37 \%)$ & $4(44 \%)$ & $1.18(0.55-2.53)$ \\
\hline $\begin{array}{l}\text { Substance abuse } \\
\text { problems combined }\end{array}$ & $86(43 \%)$ & $8(89 \%)$ & $1.46(1.11-1.90)$ \\
\hline
\end{tabular}

general way, the normalisation of imprisonment is likely to have adverse effects on the expectations and aspirations of children and adults. It adds also to the stigma attached to Travellers as a group.

Heron et al report that Traveller women have high levels of psychological distress, higher in those with the worst accommodation and environmental facilities. ${ }^{14}$ Travellers admitted to the Central Mental Hospital had less severe mental illness than white Europeans, and more learning disability. This distinguishes them from other ethnic minorities in the same series who showed a marked excess of severe mental illness when compared with white Europeans.

Imprisoned Travellers are significantly more likely to report problems with drugs and alcohol. Self-report is a soft measure, but it is a reflection of willingness to accept treatment. This does not prove that all Travellers as a group have a higher prevalence of drugs and alcohol problems, but it suggests that they may be more likely than the settled population to be imprisoned if they have a drugs or alcohol problem. This may reflect the difficulties Travellers experience in accessing drug and alcohol services.

Travellers show a high utilisation of general practitioner and accident and emergency services, and a low utilisation of other hospital services including aftercare, preventive services and specialised services such as psychiatric care. Low levels of literacy and a nomadic lifestyle have been identified as barriers to Travellers gaining access to the health services.

Prejudice on the part of the general public and service providers may also result in Travellers being refused access to health services. ${ }^{15}$ Little is known concerning the extent to which Travellers are over or under-represented in general adult psychiatric services. Less is known regarding the true prevalence of mental illnesses in the Traveller population.

The systematic induction into prison of a significant proportion of any identifiable group within society is a cause for concern. From a mental health perspective, prisoners have an increased risk of suicide. ${ }^{16-18}$ And prisoners have more mental health problems than the general population. ${ }^{19}$ Use of injected drugs and infection with hepatitis $C$ and other viruses are endemic in Irish prisons, and only a small number of first time prison entrants were infected with one or more of the blood-borne viruses. ${ }^{13}$

Imprisonment disrupts work, education, marriage and parenting in ways that are harmful to the prisoner and to the prisoner's family. ${ }^{20}$

In any ethnic group or sub-population where imprisonment is so common, it is reasonable to hypothesise for future research that the lowered life expectancy, the impaired physical and mental health, may to some extent be caused by imprisonment itself.

A practical consequence would be to use contact with the criminal justice system as a means of engaging individuals in culture-specific programmes for health promotion, examples of which can be found in other jurisdictions. In Canada, ${ }^{21}$ Australia and New Zealand, ${ }^{22,23}$ indigenous minorities are also over-represented in prisons and forensic psychiatric institutions. Approaches to specific services ${ }^{24}$ and training ${ }^{25}$ have been described and should be considered in the Irish mental health services and also in the lrish courts and prison service.

\section{Declaration of Interest: None.}

\section{References}

1. Cope R, Ndegwa D. Ethnic differences in admission to a regional secure unit. J Forensic Psychiatry 1991; 1 : 365-368.

2. Coid $\mathrm{J}$ et al. Ethnic differences in admissions to secure forensic psychiatry services. Br J Psychiatr 2000; 177: 241-247.

3. Home Office. Race and the Criminal Justice System: A Home Office Publication under Section 95 of the criminal justice Act 1991. London: Home Office

4. Donziger SR. The Real War on Crime. The Report of the National Criminal Justice Commission. New York: Harper Perennial, 1992.

5. Pavee Point Traveller Centre. Fact Sheet on Irish Travellers; 2001. (www.paveepoint.ie)

6. O'Connell J. Travellers in Ireland: An Examination of Discrimination and Racism. A Report from the National Co-Ordinating Committee for the European Year Against Racism. 1997.

7. Barry J, Herity B, Solon J. Vital statistics of Travelling people. Dublin: The Health Research Board, 1987

8. Government of Ireland. Report of the Task Force Report on the Travelling Community. Dublin: Stationery Office, 1995.

9. Goffman E. Stigma: notes on the management of spoiled identity. New Jersey: Prentice-Hall, 1963.

10. Gunn J, Bonn J. Criminality and violence in epileptic prisoners. Br J Psychiatr 1971; 118(544): 337-43.

11. Traveller Accommodation Unit. Department of Environment and Local Government, 11. Traveller Acco
Dublin 1999.

12. Central Statistics Office . Statistical Special Release: The Demographic situation of the Traveller Community in April 1996. Government Publications Office, Dublin 1998 13. Long J et al. Prevalence of antibodies to hepatitis B, hepatitis C, and HIV and risk factors in entrants to Irish prison: a national cross sectional survey. BMJ 2001; 323: 1-6. 14. Heron et al. The psychosocial health of Irish Traveller mothers. In: MacLachlan M, O'Connell M (eds). Cultivating pluralism: psychological, social and cultural perspectives on a changing Ireland. Dublin: Oak Tree Press, 2000.

15. McCarthy P et al, Centre for Health Promotion Studies, University College Galway. Health Service Provision for the Travelling Community in Ireland: Dublin, Stationery Office, 1995.

16. Dooley E. 1Prison Suicide in England and Wales 1972-1987. Br J Psychiatr 1990; $156,40-45$.

17. O'Brien B (chair). Report of the Advisory Group on Prison Deaths. Dublin: The Stationary Office, 1991.

18. Woods J (chair). Report of the National Steering Group on Deaths in Prisons. Dublin: The Stationary Office, 1999.

19. Hannon F, Kelleher C, Friel S. General healthcare study of the Irish prisoner population. Dublin: The Stationary Office, 2000.

20. Shaw R. Children of imprisoned fathers. London: Hodder \& Stoughton, 1987.

21. Phillips, MR, Inui TS. The interaction of mental illness, criminal behaviour and culture: native Alaskan mentally ill criminal offenders. Cultural Med Psychiatr 1986; 10(2): $123-$ 49.

22. Albrecht $H$, Cheplow D, Peters J. Forensic psychiatry and prison liaison services in Auckland: the first twelve months. NZ Med J 1992; 105: 334-5.

23. Brinded PM et al. Prevalence of psychiatric disorders in New Zealand prisons: a national study. Aust NZ J Psychiatr 2001; 35: 166-73.

24. Hunter $E$. Is there a role for prevention in aboriginal mental health? Aust J Public Health 1995; 19 (6): 573-579.

25. Johnstone K, Read J. Psychiatrist's recommendations for improving bicultural training and Maori mental health services: a New Zealand survey. Aust NZ J Psychiatr 2000; 34: 135-45 